\title{
Alcohol Consumption and Life Satisfaction: Evidence from Russia
}

\section{Krekhovets E.,}

National Research University Higher School of Economics, Researcher, Lab for Institutional Analysis, Centre for Institutional Studies, Higher School of Economics, Moscow, Russia.

Leonova L.,

National Research University Higher School of Economics

Doi:10.5901/ajis.2013.v2n8p98

\section{Abstract}

Alcohol consumption is known to have an impact on various aspects of individual's life. This paper is based on the idea that the alcohol consumption is very likely to influence on subjective well-being. Using data from the Russia Longitudinal Monitoring Survey of HSE (RLMS-HSE) in this paper the links between alcohol consumption and subjective well-being is examined. RLMS-HSE data shows that a significant number of individuals consumed alcohol in the last month in Russia, the proportion of men drinkers is extremely high, and is around 60-70\%. Two sources of endogeneity are discussed in the paper: individual characteristics, such as one's value system and traits of character; and the existing environment, for example, a negative macroeconomic situation. Empirical estimates are obtained using probit adapted OLS approach. Results suggest that reasonable consumption of alcohol improves the level of life satisfaction. However, alcohol abuse produces negative effects on life satisfaction.

Keywords: alcohol consumption, subjective well-being, probit adapted OLS approach

\section{Introduction}

Alcohol consumption is known to be one of the most important problems in today's society. The concerns are obvious: according to the World Health Organization, about 2.5 million people die every year because of alcohol abuse.

Alcohol consumption has an impact on various aspects of a person's life: not only on one's health and mortality rate but also on social life, economic activity and subjective well-being. Numerous studies found ample evidence of the drinking habit impact on individual lives. It is accepted in economic literature to classify alcohol drinkers into two groups: heavy drinkers and moderate ones. Empirical research shows that the effect of alcohol consumption depends on the degree of drinking. For abstainers and heavy drinkers alcohol consumption leads to reductions in productivity and earnings and to decrease in subjective well-being. On the other hand, moderate drinkers increase their productivity and earnings and feel happier.

Alcohol consumption in Russia is known to be one of the most serious social problems. Struggle against alcoholism has a long history. Today the government is introducing special programs and measures to decrease alcohol drinking, particularly, among the youth. Alcohol abuse is believed to destroy human capital and considerably expand social costs.

The outline of this paper is as follows: the second part of this article reviews the literature examining the correlation between alcohol consumption and economic and social indicators. The third part analyses some statistics of alcohol abuse and describes the data used to estimate the model. The next part of the article gives preliminary results of examining the model of alcohol drinking impact on subjective well-being with the help of RLMS. The final part is a conclusion.

\section{Literature review}

Alcohol consumption is a field of research agenda for economists and social scientists. Drinking influences all aspects of an individual's life: health, social and economic life.

From the economic point of view, it is interesting to study the correlation between alcohol consumption and labor market indices. Drinking alcohol can affect a worker's productivity and a person's earnings. Alcohol consumption also 
influences human capital. One of the earlier investigations which estimated the consequences of alcohol consumption was the book by Irving Fisher published in 1926 (Fisher, 1926). The author studied the effects of alcohol consumption on a worker's productivity. The results showed that drinking alcohol has an unfavorable influence on productivity, it reduces proficiency and speed of some tasks fulfillment. Fisher, in particular, remarks that three glasses of beer per day lower productivity by about 10 percent.

Recent research has also found evidence of baleful influence of alcohol consumption on productivity. Estimating the effects of alcohol and other substances abuse Rohm et al (2007) underlined that indirect cost of productivity losses was the largest part of total cost $(61 \%$ or $\$ 24.4 \mathrm{bn}$.).

Numerous modern economic researchers study the impact of alcohol consumption on workers' earnings. Some economists believe that there is no substantial correlation between drinking and personal wages, other studies show a strong link between alcohol drinking and earnings. Berger and Leigh (1988) formulate the wage equation for drinkers and nondrinkers using the Quality of Employment Survey and conclude that drinkers earn more than nondrinkers.

More recent studies find that not all drinkers earn more but only moderate ones. Hamilton and Hamilton divide all drinkers into three groups: heavy drinkers, moderate drinkers and light ones. The study shows that heavy alcohol consumption results in the decrease in wages, while the wages of moderate drinkers rise (Hamilton V., and Hamilton B., 1997). The results concerning the increase in wages of moderate alcohol drinkers are confirmed by the study by Heien (1996), in which he examines the data of US workers from 1979-1984. The same results are obtained by French and Zarkih (1995) in their survey of US workers. They ascertain that drinkers who consume from 1.5 to 2.5 drinks per day earn more than abstainers or heavy drinkers.

Another well-known study which examines the correlation between alcohol consumption and earnings is the article Kenkel D.S., Ribar D (1994). There, the authors show how alcohol consumption influences a worker's wage. To illustrate it they devise two variables: "days drinking" - how many days the respondent drank in the past month and "heavy drinking" - how many days the respondent drank more than six drinks. The results indicate that the effects of the variable depend on the sex. For men there is negligible or no effect of "days drinking" and there is small effect of "heavy drinking". However for women the effect of "days drinking" is small but positive and "heavy drinking" indicates no effect.

Lee and Hirschberg (2004) examine the effect of pernicious habits on wages. The authors consider not only alcohol consumption but also smoking. Using the Australian National Health Survey, they create the model which analyzes the correlation between alcohol consumption, smoking and wages. The sample includes data of two groups smokers and non-smokers. For non-smokers the result is the same as in the previous research. Moderate drinkers earn more than either abstainers or heavy drinkers. But the data on smokers shows that there is no significant correlation between alcohol consumption and wages.

A huge group of modern researchers try to estimate social costs of alcohol consumption. Anderson and Baumberg (2006) find that tangible social cost of drinking in Europe in 2003 was about 1.3\% of the GDP. The total tangible cost is divided into nine parts. More than a quarter of the total cost is the cost of mortality ( $€ 36 \mathrm{bn}$.), health and medical costs make up about $19 \%$ of the total cost, crime-related costs - 35\% of the total cost and economic costs such as unemployment and absenteeism take $20 \%$ of the total cost. Furthermore, the intangible cost is also estimated in this research. The intangible cost includes "the value of people place of pain, suffering and life itself due to crime and lost healthy life due to alcohol"; and drinking causes about €152bn - €764bn in terms of intangible cost. The intangible cost cannot be compared with monetary indicators such as the GDP but it shows a more comprehensive view of alcohol consumption effects.

There are similar studies of alcohol consumption influence on social cost in other countries. The estimated effects of alcohol consumption, smoking and illegal drug using in Canada in 2002 show that the total social cost of misusing was about $\$ 40 \mathrm{bn}$ or $\$ 1267$ of the total cost per capita (Jurgen Rehm et al, 2007). About 37\% of the total cost was connected with alcohol drinking. The investigation finds that substance use and misusing, upon the whole, and alcohol consumption, particularly, produce a huge negative effect on the Canadian economy and society. For the Australian economy the effect of drinking alcohol is also enormous. According to the research of Collins and Lapsley (2008), the total social cost of alcohol consumption in Australia in 2004-2005 was $\$ 15.3 \mathrm{bn}$ and one third of this cost was intangible (\$4.49bn.).

Another area of researching alcohol consumption effects is estimating the influence of alcohol drinking on human capital. Some studies examine the impact of alcohol consumption among young individuals and determine that drinking alcohol leads to decrease in time spent on studying and early termination of schooling and results in negative consequences for the future labor market. Mullahy and Sindelar (1989) use a sample group of men aged 25-59 to analyses the outcomes of teenage alcohol consumption. They find that teenage alcohol dependence causes early termination of schooling. The same reduction in the probability of high-school graduation is also found in the research of 
Yamada, Kendix and Yamada (1996) and in the study of Cook and Moore (1993). The supposition that education years are reduced because of alcohol use is confirmed. In 2001 Koch and Ribar (2001) investigate the correlation between completed years of schooling and alcohol drinking using the sample from the NLSY. They find out that the earlier a person starts to drink alcohol the fewer grades of education he completes.

The empirical model of Williams, Powell and Wechsler (2003) examines two effects of teenage alcohol consumption. They divide the influence of alcohol consumption into direct and indirect effects on human capital. The direct effect is a college student's GPA and the indirect one is the hours spent on studying. Using the data from Harvard School of Public Health College Alcohol Study, the authors reveal a surprising result that "drinking has a small positive direct effect on GPA". On the other hand, the model shows that alcohol consumption negatively influences the hours spent on studying, thereby the indirect effect prevails over the direct one. Therefore, the net effect of alcohol drinking among students according to the research is comparatively small.

Some researchers consider health a constituent part of human capital. Grossman (1972) believes that health as a part of total human capital determines how much time people can spend on earning. Becker (2007) also defines human capital not only as education and job training but also as health. In this way the impact of alcohol consumption on human capital is quite obvious. According to the research, there are a lot of health problems associated with alcohol consumption. Drinking causes such diseases as liver damage, heart diseases, some forms of cancer, high blood pressure and others. But some investigations produce surprising results according to which deaths provoked by alcohol consumption among moderate drinkers are less common than among non-drinkers and heavy drinkers. Multiple medical studies observe the interdependence between alcohol drinking and deaths for different age, sex, geographic and ethnic groups (Coate D., 1993, Delabry L., Glynn R., Levenson R., Hermos M., LoCastro J., Vokonas P., 1992, Jackson R., Scragg R., Beaglehole R., 2004, Razay G., Heaton K., Bolton C., Hughes A., 1992).

One of the modern tendencies is examining the correlation between alcohol consumption and life satisfaction. The growing interest in the study of subjective satisfaction data can be explained by the development of econometric methodology, on the one hand, and applicability of the theory to some economic models, on the other. Massin and Kopp (2010) use Russian panel data to estimate the influence of drinking on subjective well-being. The investigation shows a U-shaped correlation between the frequency of alcohol consumption and happiness. The American researcher Graham (2008) also mentions alcohol consumption as a determinant of subjective satisfaction.

In economic literature, the effects of alcohol consumption on different parts of personal and social life have been examined. Recent researches show that the impact of alcohol consumption depends on the frequency and quantity of drinking. For moderate drinking the effect is positive: the productivity increases, a person earns more and feels happier. But for abstainers and heavy drinkers the results are opposite. In any case alcohol consumption affects human capital and causes huge social costs.

\section{Data and descriptive statistics}

The statistics for 2005 stated that alcohol consumption was about $30 \%$ of the total worldwide consumption. Governments and international institutes address the issue of high alcohol consumption. As it can be seen in figure 1, the total consumption of alcohol decreased in the recent years from 1192.32 liters per capita in 2005 to 1156.15 liters per capita in 2007. Unfortunately, this $3 \%$ decrease is too small in comparison with more than a $12 \%$ increase of alcohol consumption in 2000.

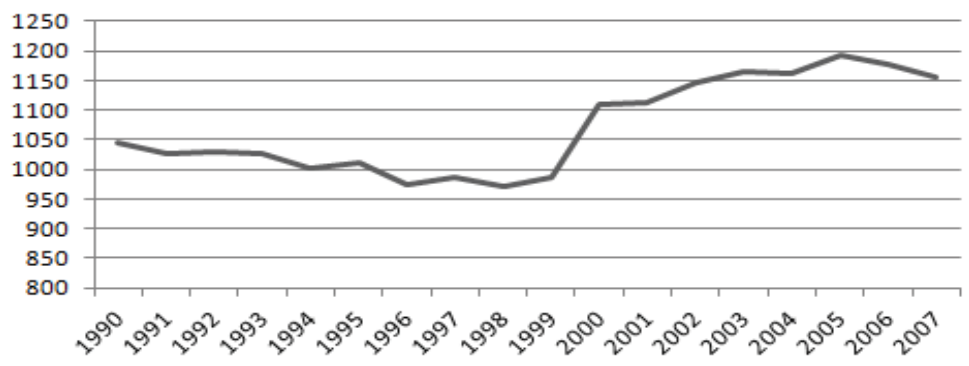

Fig. 1. Registered adult (15+ years) per capita consumption (in liters of pure alcohol), from the WHO The World Health Organization divides all types of alcoholic beverages into four groups: beer, wine, spirit and others. 
Figure 2 shows that in 2005 beer was the most popular type of alcohol in the world, spirit was in the second and wine in the third place respectively. These three types of alcohol accounted for about $97 \%$ of total alcohol consumption.

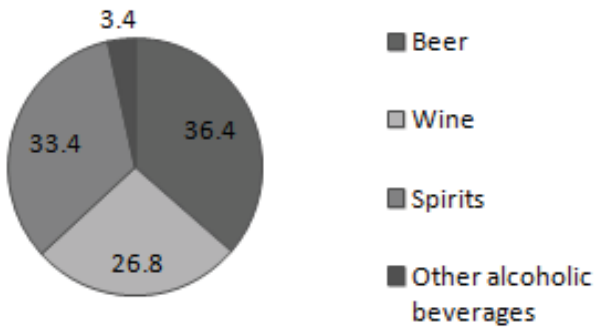

Fig. 2. Consumption of pure alcohol by type of beverage (\%), from the WHO

There are a lot of myths about Russians, but sometimes these myths have evidence. Russians are known to be the most drinking nation. This fact is supported by regrettable recent statistics. The Federal State Statistics Service of the Russian Federation provides some interesting data on consumption of alcohol in Russia. The next figure shows sales of alcohol and beer in Russia in the post-Soviet period.

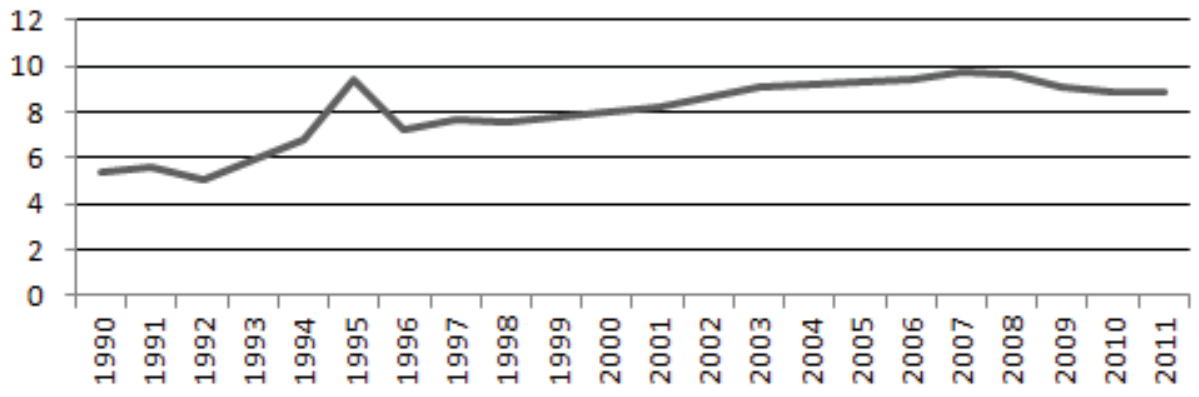

Fig. 3. Sale of alcohol and beer in liters per capita, from FSSS

According to the graph, there is a growing trend in alcohol and beer sales in modern Russia. In the nineties the average growth of alcohol and beer sales was about 4.2\%. A sharp increase in the sales took place in that period: in 1995 the sales rose by $39 \%$ but then they dropped by $23 \%$ at the end of 1995 . In the next decade the growth rates slightly reduced from 4.2 to 1.1\%. Moreover, we can see a decrease in alcohol and beer sales from 2008 to 2011. Upon the whole, the sales of alcohol and beer increased by more than 64\% from 1990 to 2011.

The empirical estimates are based on the Russian Longitudinal Monitoring Survey of HSE (RLMS-HSE) data -a panel survey for Russia. RLMS-HSE contains information on the income, socio-demographic characteristics of households and individuals. Additionally, the data set provides information on the subjective assessments of well-being, such as satisfaction with the job and life. The time interval is restricted to the period from 2005 to 2011 . Most respondents were interviewed annually in October-November. The original sample for 2005 contains data on a little fewer than 5,500 individuals.

Life satisfaction is a dependent variable in this study. It is an answer to the question of how much the respondents are satisfied or not satisfied with their life in general. The answer has five gradations: "Completely satisfied", "Quite satisfied", "Partly satisfied", "Not very satisfied", "Not satisfied at all". These answers are presented as a gradationordered discrete scale of 1 to 5 for empirical analysis, the higher the value, the more the individual is satisfied with life. 


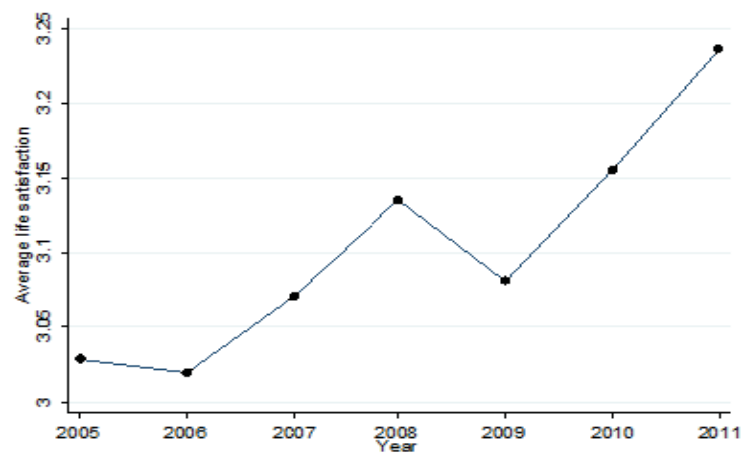

Fig. 4. Mean level of life satisfaction, Source: RLMS-HSE 2005-2011.

The set of explanatory variables includes the main socio-demographic characteristics (gender, age, marital status, level of education). The main focus of our attention is the variables that characterize the individual's attitude to consumption of alcohol: the dummy variable accounting for alcohol consumption in the past 30 days and the frequency of alcohol use in the past 30 days (the discrete variable from alcohol consumption once in the last 30 days prior to the use of alcohol every day).

RLMS data (Figure 5) shows that a significant number of individuals consumed alcohol in the last month, the proportion of men drinkers is extremely high, and is around 60-70\%. In 2000- 2001 there was an increase in the percentage of respondents who consumed alcohol, and then the value of the indicator tends to decrease slowly.

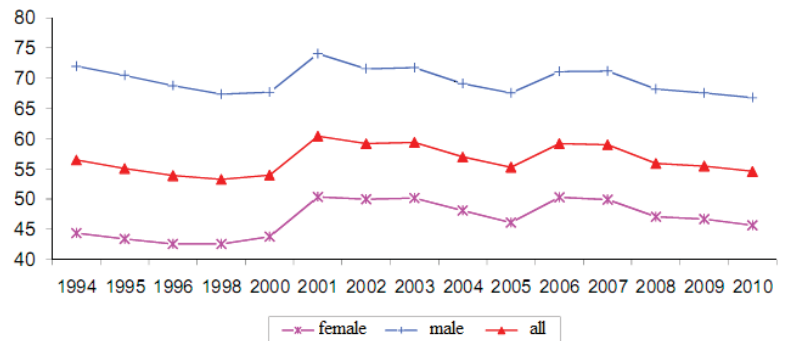

Fig. 5. The proportion of men and women over 16 who consumed alcohol in the last 30 days before the survey, $\%$, RLMSHSE, Source: Roshchina Y., 2012.

\section{Empirical results}

Life satisfaction can be treated as proxy utility. The goal of this paper is to examine the correlation between life satisfaction and alcohol consumption, to clarify how alcohol consumption affects an individual's subjective well-being.

Two sources of endogeneity can be identified in the analyzed problem.

Firstly, individual characteristics, such as one's value system and traits of character, may affect not only the level of life satisfaction, but also the choice of employment status.

Secondly, the existing environment, for example, a negative macroeconomic situation, may also correlate with a person's views and attitude to alcoholic beverages.

The first problem can be solved by employing panel data analysis with a fixed-effects approach, as it eliminates the effect of the individual's invariable personal traits.

An inclusion of annual dummy variables into the regression model to monitor the effect of the economic environment can help cope with the second problem.

Psychological studies indicate that job details and profit form the utility function in a complicated way. Life satisfaction is highly influenced by personal traits and other unobservable individual aspects. In other words, it may be assumed that perceptions of ordinal life satisfaction scale vary for individuals. Estimates of pooled regressions presuppose the correlation between individual effects and other explanatory variables. FE model in this case could fix the problems of pool and RE models' inconsistencies. 
Maximum likelihood estimates of FE logit model can be assessed only on the subsamples of those individuals for whom there is time variation of dependent variable. Therefore, the sample size is usually reduced considerably, especially in the case of an ordinal dependent variable.

To cope with the problem of shrinking sample as a result of using FE models, we implement the so-called probit adapted OLS approach. This method proposed by van Praag\&Ferrer-i-Carbonel (2008), consisting in rescaling the ordinal variable or "rough cardinalisation" in order to use linear models, would be more justified.

The "cardinalised" dependent variable is constructed by taking the expectation of a standard normally distributed variable under the condition that it is in the interval between those two Z-values that correspond to the class of the value of the original variable (Cornelißen, 2006).

In this method, Z-values of the standard normal distribution can be replaced with cut-off points taken from the ordered probit regressions.

After the "cardinalisation" process, linear FE model is estimated. Thus, this approach allows us to take into account the presence of unobservable individual effects and their correlation with regressors, and, at the same time, avoid the problems of the sample decreasing.

In order to check the robustness, we first estimate an ordered probit model without taking into account the panel nature of the data, and then apply the probit adapted OLS procedure.

Table 1. Determinants of life satisfaction

\begin{tabular}{|c|c|c|c|c|}
\hline \multirow{3}{*}{$\begin{array}{l}\text { Dependent variable: life satisfaction } \\
\text { Variables }\end{array}$} & \multicolumn{4}{|c|}{ Specification } \\
\hline & \multicolumn{2}{|c|}{ Probit adapted OLS } & \multicolumn{2}{|c|}{ Polled ordered probit } \\
\hline & I & II & III & IV \\
\hline Alcohol consumption & 0.048 & - & $0.157^{\star \star \star}$ & - \\
\hline Frequency of alcohol consumption & - & -0.019 ** & - & $-0.030^{\star \star \star}$ \\
\hline Income (logarithm) & $0.023^{\star \star \star}$ & $0.022^{\star \star \star}$ & $0.061^{\star \star \star}$ & $0.061^{\star \star \star}$ \\
\hline Male & - & - & $0.093^{\star \star \star}$ & $0.119 * \star \star$ \\
\hline Age & -0.036 & -0.036 & $-0.060^{\star \star \star}$ & $-0.060^{\star \star \star}$ \\
\hline $\mathrm{Age}^{2} / 100$ & 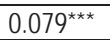 & 0.079 & $0.063^{\star \star \star}$ & $0.063^{\star \star \star}$ \\
\hline Marriage & $0.084^{* *}$ & $0.083^{\star *}$ & $0.296^{\star \star \star}$ & $0.294^{\star \star \star}$ \\
\hline Number of children & 0.000 & 0.000 & 0.000 & 0.000 \\
\hline Health & $0.069^{\star \star \star}$ & $0.069 * \star \star$ & $0.208^{\star \star \star}$ & $0.207^{\star \star \star}$ \\
\hline Confidence in the future & 0.000 & 0.000 & 0.000 & 0.000 \\
\hline Concern & 0.000 & 0.000 & 0.000 & 0.000 \\
\hline Year $2005^{1}$ & 0.073 & 0.069 & $-0.234^{\star \star \star}$ & $-0.239^{* \star *}$ \\
\hline Year 2006 & 0.047 & 0.047 & $-0.235^{\star \star \star}$ & $-0.236^{\star \star \star}$ \\
\hline Year 2007 & 0.031 & 0.031 & $-0.204^{\star \star \star}$ & $-0.203^{\star \star \star}$ \\
\hline Year 2008 & 0.002 & 0.003 & $-0.178^{\star \star \star}$ & $-0.175^{\star \star \star}$ \\
\hline Year 2009 & -0.060 & -0.059 & $-0.228^{\star \star \star}$ & $-0.228^{\star \star \star}$ \\
\hline Year 2010 & -0.077 & -0.077 & $-0.162^{\star \star \star}$ & $-0.164^{\star \star \star}$ \\
\hline Education dummy & \multicolumn{4}{|c|}{4 categories } \\
\hline Regional dummy & \multicolumn{4}{|c|}{8 categories } \\
\hline Occupation dummy & \multicolumn{4}{|c|}{8 categories } \\
\hline Constant & -0.657 & -0.556 & - & - \\
\hline Pseudo R2 & & & 0.029 & 0.029 \\
\hline $\mathrm{R}^{2}$ within & 0.0098 & 0.0101 & & \\
\hline $\mathrm{R}^{2}$ betweeen & 0.0002 & 0.0003 & & \\
\hline $\mathrm{R}^{2}$ overall & 0.0001 & 0.0001 & & \\
\hline Number of observations & 19734 & 19734 & 19374 & 19734 \\
\hline Number of groups & 8750 & 8750 & & \\
\hline
\end{tabular}

Note: significance leve $\left.\right|^{\star}-p<.1,{ }^{\star \star}-p<.05,{ }^{\star \star \star}-p<.01$

Source: RLMS-HSE 2005-2011.

\footnotetext{
${ }^{1}$ Dummy variables for years, base year is 2011.
} 
In addition to the described empirical analysis, pooled ordered probit model with Heckman sample selection correction was also estimated as robustness check as the frequency of alcohol use is observable only for individuals who consumed alcohol in the past 30 days. But the selection equation does not make it possible to explain the fact of alcohol consumption through any observable variables; that leads to identical results of the basic equation of life satisfaction in the Heckman model and probit ordered model without correction of selection bias.

Individuals who consumed alcohol are more likely to be completely satisfied with their life in the case of ordered model estimation. However, when we try to take into account the invariable individual characteristics, and thus deal with the problem of endogeneity, the coefficient of the dummy variable, accounting for the alcohol consumption, is not significant in the fixed-effects model. But there is much probability in the assumption that the insignificance of the analyzed coefficient is caused by a small share of people moving from the category of drinkers to the category of nondrinkers and vice versa.

The influence of frequency of alcohol consumption on life satisfaction is significant and robust across different econometric techniques. On average, the more frequently a person consumes alcohol, the lower is the satisfaction with life, ceteris paribus.

These results may indicate that reasonable consumption of alcohol improves the level of life satisfaction. However, alcohol abuse produces negative effects on life satisfaction. These results are particularly important for Russia as a country with a high level of alcohol consumption.

\section{Conclusion}

In this paper, the correlation between alcohol consumption and life satisfaction was examined. In Russia the problem of alcohol abuse and its negative social consequences is particularly relevant. When we analyze the performance indicators of subjective well-being, there almost always arises the question of endogeneity, mainly caused by the undeniable influence of an individual's personal traits. Certainly, personal characteristics of a person related to the background and the attitude to life partly determine consumption of alcoholic beverages. In this study, the models with fixed effects were chosen in an attempt to cope with the problem of endogeneity. However, due to the discrete dependent variable, life satisfaction, and the inability of estimation with the ordered models with fixed effects, the empirical analysis was conducted with the "rough cardinalisation" or probit adapted OLS approach. Empirical estimates are based on the Russian Longitudinal Monitoring Survey of HSE (RLMS-HSE) data. The result was that the inclusion of the invariable individual characteristics leads to insignificant influence of alcohol consumption in the past 30 days on life satisfaction, but that may be caused by a small share of people moving from the category of drinkers to the category of non-users or vice versa. On average, the more frequently a person consumes alcohol, the lower is the satisfaction with life, ceteris paribus. The results confirm the urgent need for state regulation of alcohol consumption and the introduction of measures to reduce the level of alcohol consumption in Russia.

\section{References}

Anderson, P. \& Baumberg, B., (2006). Alcohol in Europe. London: Institute of Alcohol Studies

Becker GS., (2007). Health as human capital: syntheses and extensions, Oxford economic paper, 59, 379-410.

Berger M., \& Leigh P., (1988). The Effect of Alcohol Use on Wages, Applied Economics, 20, 1343-1351.

Coate D., (1993). Moderate drinking and coronary heart disease mortality: evidence from NHANES I and the NHANES follow-up, American Journal of Public Health 83, 888-890.

Collins DJ., \& Lapsley HM., (2008). The avoidable costs of alcohol abuse in Australia and the potential benefits of effective policies to reduce the social costs of alcohol, Australian Government Department of Health and Ageing, Monograph Series № 40.

Cook. P.J. \& Moore, M.J., (1993). Drinking and Schooling, Journal of Health Economics, 12, 411-429.

Delabry L., Glynn R., Levenson R., Hermos M., LoCastro J., \& Vokonas P., (1992). Alcohol consumption and Mortality in an American Male population: Recovering the U-shaped Curve findings for a Normative aging study, Journal of Studies on Alcohol, 53, 25-32.

French M., \& Zarkin G., (1995). Is moderate Alcohol Use related to Wages? Evidence from four worksites, Journal of Health Economic, 14, 319-344.

Graham C., (2008). "Happiness, economics of." The New Palgrave Dictionary of Economics. Second Edition. Eds. Steven N. Durlauf and Lawrence E. Blume. Palgrave Macmillan

Grossman M., (1972). On the Concept of health capital and the demand for health, Journal of political economy, 80, 1972, $223-255$.

Hamilton V., \& Hamilton B., (1997). Alcohol and earning: Does drinking Yield a Wage Premium, Canadian Journal of Economics, 30, 135-151.

Heien D., (1996). Do Drinkers earn Less?, Southern Economic Journal, 63, 60-68.

Irving Fisher (1926). Prohibition at Its Worst ,New York: Macmillan. 
Jackson R., Scragg R., \& Beaglehole R., (1991). Alcohol consumption and risk of coronary heart disease, British Medical Journal, 303, 211-216.

Jenny N Lee, \& Joe Hirschberg, (2004). Alcohol consumption, smoking and wages, Applied Economics, 36, 1807-1817.

Jurgen Rehm, William Gnam, Svetlana Popova, Dolly Baliunas, Serge Brochu, Benedikt Fischer, Jayadeep Patra, Anna SarnocinskaHart, \& Benjamin Taylor, (2007). The Costs of Alcohol, Illigal Drugs and Tobacco in Canada, 2002, Journal of Studies on Alcohol and Drugs, 68.

Kenkel D.S., \& Ribar D., (1994). Alcohol consumption and young adults' socioeconomic status, Brookings Papers on Economic ActivityMicro June, 119-161.

Koch, S. F. \& Ribar, D. C., (2001). A Siblings Analysis of the Effects of Alcohol Consumption Onset on Educational Attainment, Contemporary Economic Policy 19, N 2, 162-74.

Massin S., \& Kopp P., (2010). Alcohol consumption and happiness: an empirical analysis using Russian panel data, work in progress.

Mullahy, J. \& J.L. Sindelar, (1989). Life cycle effects of alcoholism on education, earnings, and occupation, Inquiry 26, 272-282.

Razay G., Heaton K., Bolton C., \& Hughes A., (1992). Alcohol consumption and its relation to Cardiovascular Risk Factors in British Women, British Medical Journal, 11, 80-83.

Roshchina Y. (2012). Dynamics and structure of alcohol consumption in modern Russia. Vestnik RLMS-HSE. 238-257.

Van Praag B. M. S., \& Ferrer-i-Carbonell A. (2008). Happiness Quantified: A Satisfaction Calculus Approach (Revised edition), Oxford: Oxford University Press.

William J., Powell LM., \& Wechsler H., (2003). Does Alcohol Consumption Reduce Human Capital Accumulation? Evidence from the College Alcohol Study, Applied Economics, 10.

Yamada, T. Kendix, M \& Yamada, T.,(1996). The Impact of Alcohol Consumption and Marijuana Use on High School Graduation, Health Economics, 5, 77-92. 